\title{
Comparison Adhesive strength of Resin Composite between Total-etch and Self- etch Techniques on Enamel After Fluoride Application
}

\author{
Widya Saraswati ${ }^{1}$, Adioro Soetojo ${ }^{1}$, Yasmin Tasya Brilyanti ${ }^{2}$ \\ ${ }^{1}$ Staff of Departement of Conservative Dentistry, Faculty of Dental Medicine, Airlangga University, Surabaya, Indonesia \\ ${ }^{2}$ Undergraduate Student of Dental Medicine, Faculty of Dental Medicine, Airlangga University, Surabaya, Indonesia
}

\begin{abstract}
Background: White Spot Lesion (WSL) is caused by Streptococcus Mutan which causes demineralization of teeth. One of the treatments of WSL is topical application of fluoride which aims to remineralize the teeth. However, if topical fluoride treatment does not give satisfactory results, alternative treatments can be made using restorative treatments, one of which is veneers. The procedure for applying veneers requires the application of an adhesive system. The adhesive system used to apply veneers is self-etch and total-etch. Several references state that the application of fluoride which aims to remineralize teeth can influence the adhesiv strength of the restorative material using self etch and total-etch techniques. Purpose: To determine the effect of composite resin adhesion strength between total-etch and self etch techniques on enamel after fluoride application. Reviews: Literature sources used in the preparation of the article through several databases with descriptions of the effects of fluoride application before total-etch and/or self etch administration. From the existing references, it was found that the application of fluoride before the total-etch system had a less significant effect on the adhesiv strength. Whereas in the self etch system, fluoride application has a significant effect on the adhesiv strength. Conclusion: More references say that the application of fluoride before the total-etch system has a better adhesive strength than the application of fuoride before the self etch system.
\end{abstract}

Keywords: total-etch; self-etch; fluoride; white spot lesion

Correspondence: Widya Saraswati, Department of Conservative Dentistry, Faculty of Dental Medicine, Universitas Airlangga, Jl. Mayjen. Prof. Dr. Moestopo No.47 Surabaya, 60132 Indonesia. E-mail: widya-s@fkg.unair.ac.id

\section{INTRODUCTION}

One of the early signs of caries formation is white spots on the enamel surface or what we usually call White Spot Lesions (WSL). WSL is caused by a continuous demineralization process without remineralization. This demineralization process is caused by acids produced by bacteria in the oral cavity, for example, Streptococcus Mutans. ${ }^{1,2}$

One of the treatments of white spot lesions (WSL) is topical administration of fluoride which aims to remineralize the teeth. Some examples of the application of fluoride include using toothpaste, fluoride varnish, mouthwash. If fluoride application does not produce results, then alternative treatments can be given in the form of composite resin restoration, one of which is veneers.

The veneer treatment work stage requires the application of etching and bonding. Some of the most common types of etching and bonding include self etch and total etch. However, the application of fluoride affects the etching process where the teeth are more resistant to acids so that the effectiveness of the etching material decreases. This causes the formation of microporosity to decrease so that the strength of the attachment also decreases. ${ }^{3}$

Based on the explanation above, it is considered necessary to know the bonding strength of the application of total etch and self etch bonding techniques on the surface of tooth enamel after application of fluoride material which is theoretically more resistant to demineralization by acids because it has undergone structural changes to fluorapatite.

\section{REVIEWS}

\section{Total etch}

Total etch is an application of etching material on dentine that removes part or all of the smear layer. ${ }^{4}$ The total etch application mechanism is by means of acid etching which removes the smear layer and hydroxyapatite crystals on the teeth, exposing the prism of the rod and eventually forming a micropores. This etched enamel has a high surface energy and allows the resin to easily penetrate into the micropores. 
The resin that has entered the micropores will polymerize to form mechanical interlocking between the resin and the enamel material which shows a fairly good bond strength on the enamel. ${ }^{5}$

\section{Self etch}

Self-etch is a bonding system that does not perform etching irrigation procedures. The mechanism of application of the etching material and primer is carried out simultaneously on the enamel. Where the self etch technique does not dissolve the smear layer. But by modifying the smear layer so that it is more permeable to the monitor. The smear layer polymerizes and bonds chemically with hydroxyapatite to form a smear plug. So that the resin monomer is easier to infiltrate into the enamel. ${ }^{5}$

\section{Fluoride}

The application of fluoride to teeth aims to strengthen teeth. Fluoride works by inhibiting the metabolism of plaque bacteria. High use of fluoride causes the formation of calcium fluoride. In this reaction, there is a direct exchange between fluoride ions and hydroxy ions, resulting in tooth enamel that is more acid-resistant and can inhibit the process of enamel damage (demineralization). ${ }^{6}$ Topical administration of fluoride can be given by using toothpaste containing fluoride, mouthwash containing fluoride, varnish, APF gel, sodium fluoride $(\mathrm{NaF}), \mathrm{SnF} 2 .^{7}$

\section{DISCUSSION}

White spot lesion (WSL) is one of the early signs of caries formation. WSL is caused by a continuous demineralization process without being balanced with remineralization. The demineralization process is caused by acids produced by bacteria in the oral cavity for example, Streptococcus Mutans. ${ }^{1,2}$ One of the WSL treatments is to present fluoride material which aims to help the tooth remineralization process.

If fluoride treatment is unsuccessful, alternative veneers can be used, the working stage requires the application of etching and bonding. Some of the most common types of etching and bonding are self-etching and total etching. Whereas the use of fluoride prior to etching and bonding has a special effect on the strength of the bond between the enamel and bonding. ${ }^{3}$

According to research, the application of etching and bonding after fluoride pretreatment can reduce the bonding strength of all types of etching and bonding. ${ }^{3,8}$ In 2012 there was a study conducted by Quock et al, 2012 and Attin et al, 2012 which examined the effect of Silver Diamine Fluoride (SDF) on the total bond strength of etch and self etch. ${ }^{9,10}$ According to Quock et al, 2012, the application of fluoride material causes a reduction in the bond strength of the total etch and self etch techniques. ${ }^{9}$ Meanwhile, according to Attin et al, 2012 said that fluoride application causes a significant decrease in the strength of the material bonds. However, this adhesion is superior to demineralized teeth and was not administered prior to previous treatment. ${ }^{10}$

In the following year a study was conducted on the effect of the CPP-ACP material on the adhesion strength of total etch and self etch. In a study conducted by Park et al, 2013, it was concluded that the application of CPP-ACP did not have a significant effect on total etch and self etch. ${ }^{11}$ So that the reduction that occurs is not too much different. However, in a study conducted by Borges et al, 2013, it was stated that giving CPP-ACP before offering total etch and self etch materials can increase the microtensile between the pits and the fissures and the enamel. ${ }^{12}$ This occurs during the action of CPP-ACP, ie the CPP group binds to calcium and phosphate and supports the regularity of the ACP group. Where calcium and phosphate which usually do not dissolve into the surrounding environment (saliva and plaque) become dissolved due to the presence of CPP. ${ }^{13}$ The self-etch system contains 10-MDP. Where these molecules can bind to the hydroxyapatite crystals that are lost due to partial demineralization and the effect of the bonding, therefore giving CPP-ACP before the application of selfetch material has no significant or no effect on the strength of the attachment. ${ }^{12,14}$

In 2014 there were several studies conducted by AlKawari and Al-Jobair, 2014; Lin et al, 2014; Bahari et al, 2014 who examined the effect of giving CPP-ACP material on the adhesion strength of total etch and self etch materials. ${ }^{15-17}$ According to research conducted by Al-Kawari and Al-Jobair, 2014 states that presenting CPPACP after application of total etch material results in better adhesion strength compared to applying CPP-ACP before applying total etch. This is because the application of CPPACP causes the teeth to be more resistant to acids so that the application of CPP-ACP before the etching material causes disruptions to the performance of the etching material. Although the application of CPP-ACP after application of acid etching resulted in a higher value of shear bond strength than when CPP-ACP was applied before the application of acid etching, there was no significant difference in the value of shear bond strength between the control group and the group given CPP-ACP before the etching. ${ }^{15}$ In addition, there is a study conducted by Lin et al, 2014 which states that the administration of CPP-ACP does not have a significant effect on total etch and self etch. In addition, after 6 months the micro tensile bond strength test values of the two etching materials were not much different. ${ }^{16}$ Furthermore, there is a study conducted by Bahari et al, 2014 which states that offering CPP-ACP does not adversely affect the attachment strength of self etch and total etch. However, the micro tensile bond strength test value of total etch is higher than that of self etch. ${ }^{17}$

In the following year 2015, there were more studies on the effect of giving tooth remineralization material on the attachment strength of total etch and self etch. Several studies stated that giving CPP-ACP did not have a significant effect on the attachment strength of total etch or self etch. ${ }^{18-20}$ This is as stated in a study conducted by Borgs et al, 2013 that self etch contains 10-MDP. ${ }^{12}$ Where 
these molecules can help influence. However, in a study conducted by Karamie et al, 2015, it was found that giving CPP-ACP increased the strength of the attachment to self etch. ${ }^{14}$ The total CPP-ACP etch caused a decrease in the strength of the attachment. This is because the total etch contains a high enough acid so that it can demineralize the entire surface of the enamel so that the CPP-ACP makes the tooth more resistant to acid so that it interferes with the effectiveness of the total etch.

In 2016 there was a study conducted by Baka et al, 2016 which concluded that the administration of CPP-ACP did not have a significant effect on the strength of the self etch attachment. ${ }^{21}$ This can be seen from the results found in the control group getting a shear bond strength value of 10.21 $\mathrm{MPa}$, while the group given the CPP-ACP had a shear bond strength value of $9.04 \mathrm{MPa}$ where these results did not have a big difference. In addition, there was research on the effect of the remineralizing agent Silver Diamine Fluoride (SDF) which gave the result that SDF administration did not have a significant effect on the attachment strength of total etch. ${ }^{22-24}$ This is because the acid contained in the total etch is quite large, $37 \%$ phosphoric acid which can cause a sediment or smear layer formed from the application of fluoride so that it does not have a significant effect on bond strength. ${ }^{23}$ At the time of application of the total etch material there is a rinsing step. This is a distinguishing factor with the self etch technique. The application of fluoride material can interfere with the ability of the primer and binder to fill the microporus present in the enamel. Flushing off this excess fluoride material is an important step to achieve optimal bonding so that the restoration is more durable. ${ }^{23}$

In 2017 there were several studies that said that giving fluoride material before the application of total etch and self etch did not have a significant effect on the attachment strength of total etch and self etch. ${ }^{25,26}$ This is because in this study the acid contained in the total etch or self etch is strong enough to remove the smear layer and fluoride deposits on the enamel surface..$^{25,26}$

In 2018 Lutgen et al, 2018 examined the effect of SDF on the attachment strength of total etch and self etch and concluded that the decreased application of SDF caused the attachment strength to the total etch and self etch techniques but in the total etch technique decreased the value of shear bond strength was not amount compared to self etch. ${ }^{27}$ Because the total etch technique has a greater and stronger acid than self etch, therefore the removal of the smear layer and sediment from fluoride is maximal in total etch compared to self etch. In the same year OrtizRuiz et al, 2018 conducted a study on the effect of fluoride varnish administration on the attachment strength of total etch. From these studies, it was found that giving fluoride varnish before application of total etch in the first 24 hours caused the attachment strength of the total etch to decrease drastically but after 7 days later the strength of the attachment recovered not much different from the group that was not treated with fluoride. ${ }^{28}$

In 2019 there was a study conducted by Nakamoto et al, 2019 which found that the concentration of fluoride given greatly influenced the attachment strength of self etch. Administration of fluoride at low concentrations did not affect the self-etch attachment. ${ }^{29}$ However, if the concentration of fluoride is high, this affects the selfadhesive bond, causing the micro-tensile bond strength test value to decrease considerably. In the same year Zhao et al., 2019 and Gupta et al, 2019 conducted a study on the effect of SDF on the attachment strength of total etch. Both studies found that administration of SDF had no adverse effect on the adhesion strength of total etch..$^{30,31}$

In 2020 there are several studies conducted by Ko Ko et al, 2020; Sakr, 2020; Yang et al, 2020.8,32,33 In a study conducted by Yang et al, 2020, it was found that SDF administration had a significant effect on the bond strength of the total etch. This is related to the ability of the total etch acid to remove smear layers and fluoride deposits. ${ }^{33}$

The majority of the above studies said that total etch was better than self-etch. This is because the acid possessed by total etch is quite large so that the ability of total etch to remove smear layers and fluoride deposits is greater than that of self etch. Therefore, the attachment strength generated by the total etch system is greater than that of self etch. ${ }^{19,22,23,26}$ There are several important things that affect the strength of the adhesion after pretreatment with fluoride material, namely the rinsing step and the concentration of the fluoride material given. Lutgen et al, 2018 and Koizumi et al, 2016 performed preparations with a diamond bur to remove residual sediment from fluoride material on teeth. But no studies have yet investigated whether doing diamond preparations increases the strength of the system. ${ }^{22,26}$

\section{CONCLUSION}

More references say that the application of fluoride before the total-etch system has a better adhesive strength than the application of fluoride before the self etch system

\section{REFERENCES}

1. Zulsantritus Z, Edrizal E, Busman B. Potensi Remineralisasi pada Pasta Gigi Berflorida dan Tidak Berflorida. B-Dent, Jurnal Kedokteran Gigi Universitas Baiturrahmah. 2019;3(2):139-144.

2. Gupta, R., Mahajan, N., Kotwal, B., Kaur, S., Kharyal, S. and Gupta, N., 2017. The Prevalence of White Spot Lesions During Orthodontic Treatment With Fixed Appliances in Jammu City. International Journal of Scientific Study. 2017; $5(7)$

3. Hudiyati, M., Chairani, S. and Rais, S.Pengaruh Jenis Fluoride Topikal Terhadap Kebocoran Mikro pada Pit and ssure sealant. Jurnal Material Kedokteran Gigi. 2016;5(1):3541.

4. Ritter, A., Boushell, L., Walter, R. and Sturdevant, C. Sturdevant's Art And Science Of Operative Dentistry. 7th ed. Elseviers; 2015

5. Migliau, G. Classification review of dental adhesive systems: from the IV generation to the universal type. Annali di Stomatologia. 2017;8(1): 1 . 
6. Kanduti, D., Sterbenk, P. and Artnik, a. Fluoride: a Review of Use and Effects on Health. Materia Socio Medica. 2016; 28(2): 133.

7. Koch G, Poulsen S, Espelid I, Haubek D. Pediatric Dentistry : A Clinical Approach. John Wiley and Sons, 2016.122

8. Sakr, O. M. Microshear bond strength of resin composite to pretreated dentin with silver diamine fluoride/potassium iodide: An in vitro study. Journal of International Dental and Medical Research.2020;13(3): 892-897

9. Quock R, Barros J, Yang S, Patel S. Effect of silver diamine fluoride on microtensile bond strength to dentin. Oper Dent 2012; 37: 610-616.

10. Attin R, Stawarczyk B, Keçik D, Knösel M, Wiechmann $\mathrm{D}$, Attin T. Shear bond strength of brackets to demineralize enamel after different pretreatment methods. Angle Orthod. 2012;82(1):56-61.

11. Park, S. Y., Cha, J. Y., Kim, K. N. dan Hwang, C. J. The effect of casein phosphopeptide amorphous calcium phosphate on the in vitro shear bond strength of orthodontic brackets. Korean Journal of Orthodontics. 2013;43(1):23-28

12. Borges, B. C. D., Catelan, A., Sasaki, R. T., Ambrosano, G. M. B., Reis, A. F. and Aguiar, F. H. B. Effect of the application of a casein phosphopeptide-amorphous calcium phosphate (CPP-ACP) paste and adhesive systems on bond durability of a fissure sealant. Odontology. 2013; 101(1):52-59

13. Busman B, Arma U, Nofriadi N. Hubungan Aplikasi Casein Phosphopeptide Amorphous Calcium Phosphate (CPP-ACP) Terhadap Remineralisasi Gigi. B-Dent, Jurnal Kedokteran Gigi Universitas Baiturrahmah. 2018;1(1):18-23.

14. Karamie M, Shirani F, Kaveh S, Talaee S, Salehi E. Shear Bond Strength of Composite to Primary Enamel Treated with Casein Phosphopeptide Amorphous Calcium Phosphate Using Total-Etch and Self-Etch Bonding Systems. Journal of Islamic Dental Association of Iran. 2015;27(2):97-103.

15. Aljobair A, Alkawari H. Effect of different preventive agents on bracket shear bond strength: In vitro study. BMC Oral Health. 2014;14(1):14-19.

16. Lin J, Zheng W, Liu P, Zhang N, Lin H, Fan Y et al. Influence of casein phosphopeptide-amorphous calcium phosphate application, smear layer removal, and storage time on resindentin bonding. Journal of Zhejiang University-SCIENCE B. 2014;15(7):649-660.

17. Bahari M, Savadi Oskoee S, Kimyai S, Pouralibaba F, Farhadi F, Norouzi M. Effect of Casein Phosphopeptideamorphous Calcium Phosphate Treatment on Microtensile Bond Strength to Carious Affected Dentin Using Two Adhesive Strategies. J Dent Res, Dental Clinics, Dental Prospects. 2014 Summer;8(3):141-7.

18. Cossellu G, Lanteri V, Butera A, Sarcina M, Farronato G. Effects of six different preventive treatments on the shear bond strength of orthodontic brackets: in vitro study. Acta Biomaterialia Odontologica Scandinavica. 2015;1(1):13-17.

19. Farokh Gisovar E, Hedayati N, Shadman N, Shafiee L. Casein Phosphopeptide-Amorphous Calcium Phosphate and Shear Bond Strength of Adhesives to Primary Teeth Enamel. Iranian Red Crescent Medical Journal. 2015;17(2).

20. Firoozmand L, Noleto L, Gomes I, Bauer J, Ferreira M. Effect of Fluoride and Simplified Adhesive Systems on the
Bond Strength of Primary Molars and Incisors. Brazilian Dental Journal. 2015;26(4):368-373.

21. BakaZ,Akin M, Ileri Z, Basciftci F. Effects of remineralization procedures on shear bond strengths of brackets bonded to demineralized enamel surfaces with self-etch systems. The Angle Orthodontist. 2016;86(4):661-667.

22. Wu DI, Velamakanni S, Denisson J, Yaman P, Boynton JR, Papagerakis P. Effect of silver diamine fluoride (sdf) application on microtensile bonding strength of dentin in primary teeth. Pediatr Dent. 2016;38(2):148-53.

23. Koizumi H,Hamama H H,Burrow M F.Effect of silver diamine fluoride and potassium iodide-based desensitizing and cavity cleaning agent on bond strength to dentine. Int $\mathrm{J}$ Adhes 2016; 68: 54-61.

24. Selvaraj K, Sampath V, Sujatha V, Mahalaxmi S. Evaluation of microshear bond strength and nanoleakage of etch-andrinse and self-etch adhesives to dentin pretreated with silver diamine fluoride/potassium iodide: an in vitro study. Indian J Dent Res. 2016;27(4):421-5.

25. Cossellu G, Lanteri V, Butera A, Laffi N, Merlini A, Farronato G. Timing considerations on the shear bond strength of orthodontic brackets after topical fluoride varnish applications. Journal of Orthodontic Science. 2017;6(1):11.

26. Santiago S, Neri J, Nojosa J, Yamauti M, Mendoca J. Pretreatment with sodium fluoride maintains dentin bond strength of a two-step self-etch adhesive after thermal stressing. The Journal of Adhesive Dentistry. 2017;19(6): 517-523

27. Lutgen P, Chan D, Sadr A. Effects of silver diammine fluoride on bond strength of adhesives to sound dentin. Dent Mater J. 2018;37(6):1003-9.

28. Ortiz-Ruiz A, Muñoz-Gómez I, Pérez-Pardo A, GermánCecilia C, Martínez-Beneyto Y, Vicente A. Influence of fluoride varnish on shear bond strength of a universal adhesive on intact and demineralized enamel. Odontology. 2018;106(4):460-468.

29. Nakamoto A, Sato T, Matsui N, Ikeda M, Nikaido T, Burrow $\mathrm{M}$ et al. Effect of fluoride mouthrinse and fluoride concentration on bonding of a one-step self-etch adhesive to bovine root dentin. Journal of Oral Science. 2019;61(1):125132.

30. Zhao IS, Chu S, Yu OY, Mei ML, Chu CH, Lo ECM. Effect of silver diamine fluoride and potassium iodide on shear bond strength of glass ionomer cements to caries-affected dentine. Int Dent J. 2019;69(5):341-7.

31. Gupta J, Thomas MS, Radhakrishna M, Srikant N, Ginjupalli K. Effect of silver diamine fluoride-potassium iodide and $2 \%$ chlorhexidine gluconate cavity cleansers on the bond strength and microleakage of resin-modified glass ionomer cement. $\mathrm{J}$ Conserv Dent. 2019;22(2):201-6.

32. Ko A, Matsui N, Nakamoto A, Ikeda M, Nikaido T, Burrow $\mathrm{M}$ et al. Effect of silver diammine fluoride application on dentin bonding performance. Dental Materials Journal. 2020;39(3):407-414.

33. Yang S, Jeong I, Kim K, Kwon J. Time-dependent effects after enamel fluoride application on an acid etching system in orthodontic bracket bonding. Clinical Oral Investigations. 2020;25(2):497-505. 